\title{
Evaluation Checklist for Managing Educational Technology Projects: The Experience of Faculty of Environmental Design in KAU, Saudi Arabia
}

\author{
Mohamed M. H. Maatouk
}

Faculty of Environmental Design, KAU, Jeddah, Saudi Arabia mmaatouk@kau.edu.sa

\begin{abstract}
The management of technology projects in academic institutions is a real problem, especially with the increase in projects' scale. Many of these projects suffered considerable delays in the plan and scheduling while others completely failed to achieve their objectives. There is a shortage in research that deals with the design of tools to help and guide the managers of technology projects in academic institutions to manage their projects efficiently. In particular, project managers are often faculty members not project managers professionals. Therefore, they need to have simple and effective means to help them assess and monitor the performance of their projects. This study tries to develop an Instructional Technology Project Evaluation Checklist (ITPEC). Then, uses this checklist to evaluate the implementation of a technology project, as a case study. Based on a comprehensive review of literature a preliminary to evaluate the in version of the check panel survey and case study evaluation. The final version of the checklist includes 48 checkpoints in the form of questions grouped into three groups according to the three phases of the project structure: Planning, Implementation, and Evaluation. Then, ITPEC was used in the evaluation of a case study implementation of an eCollege Project, which was implemented at the Faculty of Environmental Design, King Abdulaziz University in Saudi Arabia. Quantitative analysis of the data derived from the application of ITPEC to the case study showed many positive aspects and also some shortcomings to be addressed in the future.
\end{abstract}

Keywords: Project management, Technology Integration, Architectural Education.

\section{Introduction}

1.1 Background Reviewed and Statement of Research Problem

We live in a rapidly and constantly changing world. So, institutions need to continually upgrade the qualities of their products and services in order to survive and prosper. Projects are the means by which new innovations can be integrated and utilized in the institutions. So, greater change equals more innovations, which in turn equals more projects. The institutions that seek progress and prosperity should own effective tools for project management, which represent a means of change. Consequently, project management is an important topic because all institutions are implementing projects to the extent commensurate with its ambitions in development and modernization ${ }^{[1]}$.

A "project" can be defined as an initiative for change aimed at achieving specific goals in a specified time frame and in a specific environmental context. The successful project aims to achieve excellence in the work to be done in four aspects: Performance, Cost, Time and Scope (PCTS) ${ }^{[1]}$. Achieving the success of the project entails the existence of effective management; project management will be responsible for facilitating the planning, implementation and follow-up for all activities that must be implemented to achieve the objectives of the project ${ }^{[1]}$. Successful project management is achieved through competent managers. Project manager should manage a variety of tasks 
related to the project such as administration of the teamwork, communication with the top management, follow-up to the budget and all the tasks of the action plan, assessment of the potential risks and preparation of appropriate solutions ${ }^{[1]}$. The project manager needs tools to assist him in evaluating the progress of the project starting from its early stages and during the implementation phases until the project is completed. The evaluation checklist is one of these tools, which can be of great benefit to the project manager if properly designed and applied.

The checklist is a reminder tool used to accomplish a specific purpose and consists of a list of items, activities and standards; when used in the evaluation of projects, they do help and guide in assembling the evidence that is used to determine the success of the project to be evaluated. In fact, the organized way in which checklist operates makes it very suitable and useful in the assessment processes where the checklist reduces the chance of forgetting important something to be checked, the checklist is simple to use for the average person with little experience, the checklist includes a lot of information on the subject to be evaluated, and therefore the checklist can contribute to the improvement of the existing standards of validity and reliability of the evaluation process ${ }^{[2]}$.

However, it is reported that despite the potential, negative impacts could result from using poorly designed or misapplied checklists. Through extensive review of published research on checklists, no information was found referring to negative effects of the use of the checklists in the assessment process ${ }^{[2]}$. In the same context, many researchers advocated the benefit of using checklists in evaluation such as ${ }^{[3-9]}$.

The management of technology projects in academic institutions is a real problem, especially with the increase in projects' scale.
Many of these projects suffered considerable delays in the plan and scheduling while others completely failed to achieve their objectives. Therefore, many of research works can be found that on obstacles of integrating new technology in academic institutions [10-19]. However, there is still a shortage in research that deals with the design of tools to help and guide the managers of technology projects in academic institutions to manage their projects efficiently. In particular, scholars indicate that project managers are often faculty members not project managers professionals. Therefore, they need to have simple and effective means to help them assess and monitor the performance of their projects ${ }^{[20]}$.

\subsection{Research Aim}

So, the aim of this study is trying to fill part of this gap through developing one of these tools, an Instructional Technology Project Evaluation Checklist (ITPEC). Also using the ITPEC in the evaluation of an eCollege Project, which was implemented at the Faculty of Environmental Design (FED) at King Abdulaziz University (KAU) in Saudi Arabia.

\subsection{Research Questions}

To fulfill this aim some research questions should be answered such as: What are items and checkpoints that should be incorporated in ITPEC? What are methods of validation for ITPEC? and How practical is the use of ITPEC in a real case study? How can ITPEC reveal points of strength and weakness as a result of evaluating the eCollege Project of FED?

\subsection{Research Methodology}

This study was based on an action research design. Action research requires positive participation of a researcher in the development projects in the academic institution during preparing his research ${ }^{[3]}$. In the current study, development of the ITPEC started by reviewing and analyzing wide range 
of literature in technology integration, project management, and evaluation checklists. The resultant checklist was applied as an evaluation tool in a case study implementation of an eCollege Project in FED where the researcher participated in the implementation process. Data from this case study was collected and analyzed using descriptive and analytical techniques.

Literature on project management such as in Ref. ${ }^{[1,10,21-29]}$ served as the basis for the formation of a preliminary version of the checklist. Validation of the preliminary checklist was based on a mixed method approach ${ }^{[2]}$, which incorporates two methods: expert panel survey and case study evaluation.

- The first method targeted an expert panel to get their feedback to develop and refine the checklist until the final (ITPEC) version was obtained.

- The second method aimed at collecting more evidence about the practicality of the checklist in the evaluation of a case study implementation of a technology project.

\section{Developing the Research Instruments}

Following is an overview of the methods and research instruments used to finalize and validate the checklist (ITPEC).

\subsection{Instructional Technology Project Evaluation Checklist (ITPEC)}

The checklist has been developed based on several literatures, then has been revised and enhanced by an expert panel as mentioned above. As shown in Table 1, the final version of the checklist ITPEC includes 48 checkpoints in the form of questions grouped into three groups according to the three phases of the project structure suggested by ${ }^{[1]}$. The three phases are Planning Phase (before starting the project), Implementation Phase (during the project), and Evaluation Phase (after completing the project). The planning phase in turn is divided into three subdivisions: Setting objectives, Organizing Actions, and Establishing Controls. The checkpoints in the checklist are scaled such as in ${ }^{[4]}$ where four answering choices were used: yes, no, to some extent, and not applicable. ITPEC is used in assessment of the achievement of a technology project as a case study; it is an eCollege Project of FED in KAU. In the next section a general background for this project will be introduced.

\subsection{Expert panel Survey}

A purposive and convenient sample was used which was comprised of ten faculty members expert in project management. A Reviewer's Form of expert panel survey was designed, as shown in Table 2, which included two parts: Part (A) which was assigned for the evaluation of the checklist, and Part (B) which was in the form of an open-ended question. All experts were asked to review the preliminary checklist for providing their feedback. Part (A) of the expert panel survey was designed to collect specific data to evaluate the checklist based on specific criteria ${ }^{[2]}$. The 5 -point scale of Likert was used to scale the responses where 1 signifies strongly disagree and 5 signifies strongly agree. Part (B) of the Reviewer's Form was an open-ended question which asked the expert panel members about any missing checkpoints, shortages, suggestions and recommendations in the purpose of enhancing the checklist. Also, Their remarks and recommendations were useful in further developing and refining of the checklist to be in its final version (ITPEC). Table 3 presents a summary of the outcome of the assessment of the expert panel for the preliminary checklist; where all the evaluation criteria lie in the range (4-5), or in other words, (Agree - Strongly Agree) with an average of 4.53, which gives a clear evidence of the possibility of using the checklist in practice. 
Table 1. Instructional Technology Project Evaluation Checklist (ITPEC).

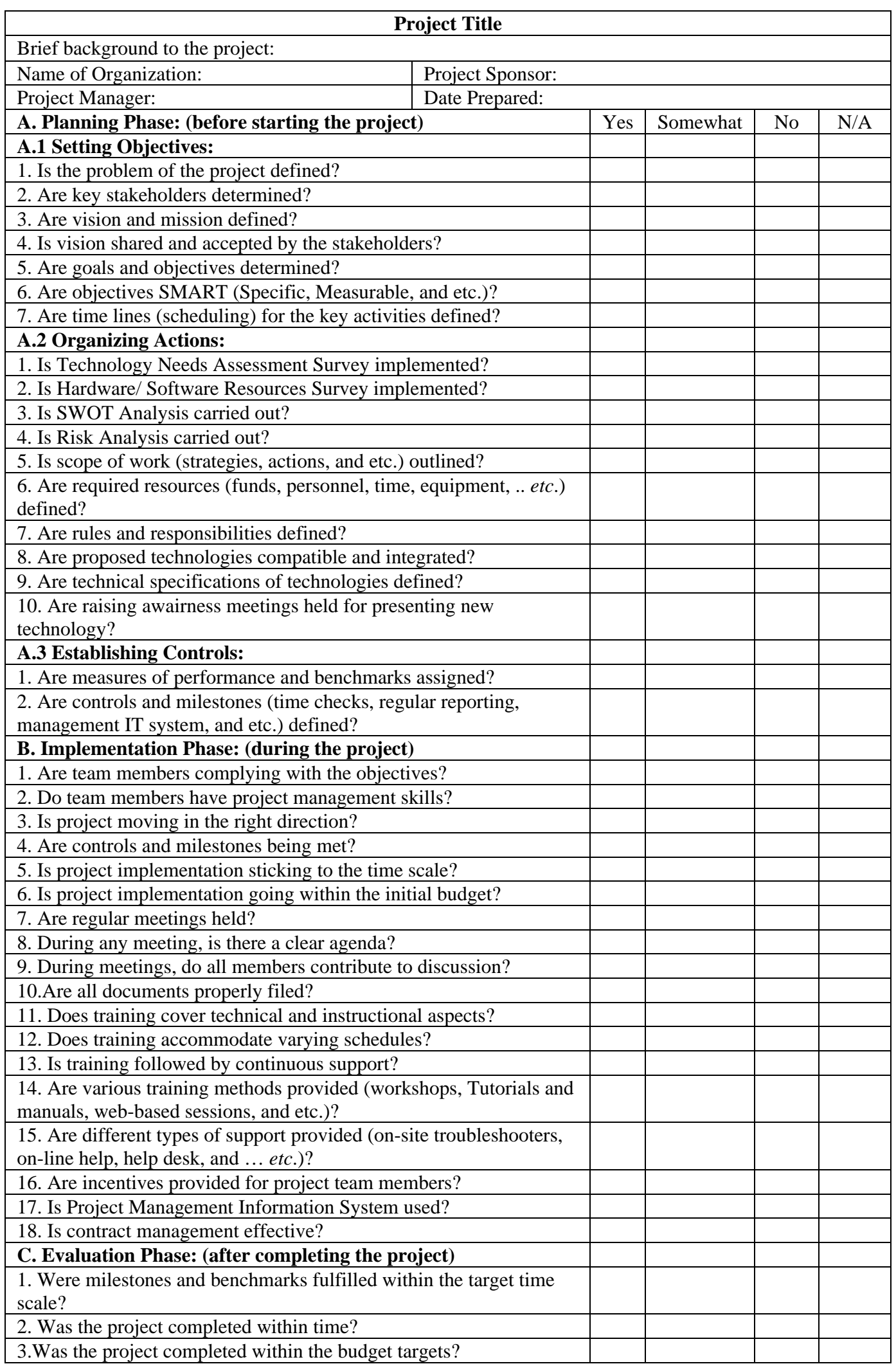


Table 1. Contd.

\begin{tabular}{|l|l|l|l|l|}
\hline 4.Were the final outcomes of the project tested? & & & & \\
\hline 5. Did project output meet client expectations? & & & & \\
\hline 6.Were resources used efficiently? & & & & \\
\hline 7. Did project receive full institutional support? & & & & \\
\hline 8. Was operating manual written? & & & & \\
\hline 9. Were client personnel trained? & & & & \\
\hline 10.Were maintenance and technical support provided? & & & & \\
\hline 11.Was final report completed (closing the project)?
\end{tabular}

11.Was final report completed (closing the project)?

Table 2. Reviewer's Form of Expert Panel Survey.

\section{A. Checklist Evaluation}

After reviewing the ITPEC, please indicate the degree to which you agree or disagree with the following evaluation criteria. (Please circle the appropriate number from 1 to 5 . Here 1 signifies "Strongly Disagree" and 5 signifies "Strongly Agree")

\section{Evaluation Criteria}

1. Checklist is workable and applicable.

2. Checklist is easy to use.

3. Checkpoints were formulated in a clear unambiguous language.

4. Checkpoints are comprehensive in addressing aspects of project management

5. Checkpoints are characterized by realism and the possibility of investigation.

6. Checkpoints are characterized by neutrality and objectivity.

7. Checkpoints were formulated briefly and specific.

8. Checkpoints were linked to the subject of the checklist.

\section{B. Suggestions and Recommendations}

After reviewing the ITPEC, are there any missing checkpoints, shortages, suggestions, and recommendations you would like to add?

Missing checkpoints:

1.

(1)

3.

4.

5. .

Shortages:

1....

3.

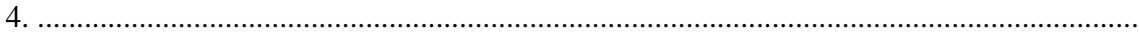

5 .

Suggestions and Recommendations:

1 .

2.

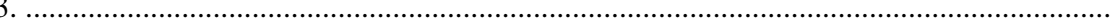

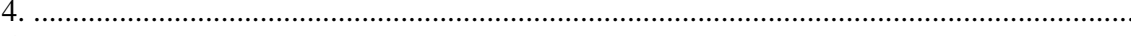

5. (1) -

6.

7.

9.

10. 
Table 3. A summary of the outcome of the assessment of the expert panel for the preliminary checklist.

\begin{tabular}{|l|c|}
\hline \multicolumn{1}{|c|}{ Evaluation Criteria* } & $\begin{array}{c}\text { Weighted } \\
\text { Mean }\end{array}$ \\
\hline 1. Checklist is workable and applicable. & 4.70 \\
\hline 2. Checklist is easy to use. & 4.40 \\
\hline 3. Checkpoints were formulated in a clear unambiguous language. & 4.10 \\
\hline 4. Checkpoints are comprehensive in addressing aspects of project management. & 4.60 \\
\hline 5. Checkpoints are characterized by realism and the possibility of investigation. & 4.60 \\
\hline 6. Checkpoints are characterized by neutrality and objectivity. & 4.90 \\
\hline 7. Checkpoints were formulated briefly and specific. & 4.30 \\
\hline 8. Checkpoints were linked to the subject of the checklist. & 4.60 \\
\hline \multicolumn{1}{|c|}{ Average } & $\mathbf{4 . 5 3}$ \\
\hline
\end{tabular}

* (Martz, 2010, P. 217).

\subsection{Case Study Evaluation}

In this step, the revised version of the checklist (ITPEC) is used in evaluation of the achievement of a realistic technology project as a case study. The purpose of the evaluation is to show possibilities of the ITPEC in practice in addition to the analysis of points of strength and weakness of the project. As already mentioned, the case study was the eCollege Project of FED, which will be shed light upon in detail in the next section. The information collected using ITPEC was obtained through personal interviews with the key managers of the eCollege project of FED, then analyzed and interpreted by the researcher using quantitative methods. The conclusion of the obtained results was discussed with the managers of the eCollege project to assess the accuracy and credibility of the results that have been reached. The managers confirmed the quality and credibility of the findings that reveal points of strength and weakness of the project.

\section{The Experience of the eCollege Project of FED (in KAU)}

Since 2006 FED started an eCollege Project which passed by three main stages are summarized as follows.

\subsection{The First Stage of the eCollege Project} (the period from 2006 to 2008)

This stage represents the original version of the eCollege Project of FED. The eCollege was visioned, planned, and established by the Dean of FED at that time ${ }^{(1)}$. The eCollege was seen as an integrated system which enables FED to process, monitor and control its activities and services effectively to increase the outcome of its faculty, students and administration. The eCollege included four key projects: eCollege Portal, eLearning, Archiving and Workflow, and IT Infrastructure. The Portal was programmed using ASP (Active Server Pages), the open resource Moodle was used as an eLearning Management System, and the eDoX software was used for Archiving and Work Flow. The IT Infrastructure Project represented the backbone of the eCollege that includes labs, servers room, networks and IT facilities. Furthermore, an executive IT Unit was established to manage the eCollege Project during all stages of implementation. The IT Unit contained faculty members, research assistants and technical persons. The first prototype of the eCollege of FED was ready to be released and presented in March 2008. Further details of that stage of the project can be found in ${ }^{[30]}$.

(1) Dr. Hosny Aziz Alrahman 


\subsection{The Second Stage of the eCollege Project} (the period from 2008 to 2010)

Although the first prototype of the eCollege Project of FED was promising, later problems of the integration with some IT standards of KAU clearly appeared. To achieve integration, a Steering Committee was established for one year. The Steering Committee had kept the main structure of the original plan of the eCollege and the main key projects (Portal, eLearning, archiving, and IT infrastructure); yet, added two branched projects: Multimedia Digital Resources, and ePortfolio of Faculty and Students. The Multimedia Digital Resources is viewed to be a big digital library available online for students' projects while the ePortfolio is a visual archive of the curriculum vitae of the faculty member or the student. Unfortunately, frequent problems with bidding processes have hindered the implementation of the visual digital library. Also, the university had provided Dr. Portal as a new e-service for faculty which partially substituted the ePortfolio. Moreover, the university has provided a group of academic and administrative e-services whereby the original plan of the eCollege was decreasing and shrinking. Perhaps the most important achievements of that stage were the full integration of FED Portal with KAU standards and the activation and establishment of Dr. Portal for almost all faculty members of FED.

\subsection{The Third Stage of the eCollege Project} (the period from 2010 to 2012)

This period was featured by increased progress in developing IT infrastructure of FED. The university stimulated and supported FED to modernize its IT facilities. Consequently, different technologies were added such as Wireless network, LCDs and Smart Boards, Interactive Smart Room, Video Conference systems, Copy Center, 3D
Scanner, and GPS Surveying Systems. Furthermore, different systems of 3D Printing and Virtual Reality were searched, evaluated, and became ready for bidding but shortages of the available spaces in the building postponed completing the purchase process. Moreover, it was clear that the eCollege Project needs consultancy and technical support from outsources. Many meetings had been held between representatives of FED with others from different IT companies such as VMware, Citrix, HP, Dell, and Fujitsu to discuss a Desktop Virtualization technology (ZeroClient communication solution). Using this technology will enable FED to establish a Data Center which has been recommended by all consultants as the backbone of the eCollege Project. The Data Center will connect all computers in studios, labs, Copy Center, offices of faculty and administrators with central servers. All users can make their applications on the central servers rather than their computers or workstations. Every piece of work can be sent and stored in the data center. The applications and stored data can be accessed and retrieved anywhere-anytime under different levels of authentications. Unfortunately, the work on the Data Center and on the whole project of the eCollege was postponed until FED moves to a new building in the campus. In the academic year 20122013, the first semester FED has moved to the new building and till now the project has not been continued yet.

\section{Discussion of Results}

Figure 1 represents the results of assessment of the eCollege Project applying the ITPEC. Checkpoints of Group C (Evaluation Phase: after completing the project) were excluded from assessment because the eCollege Project was not completed yet. The produced pie chart shows that ratio of positive checkpoints is about $65 \%$, 
ratio of negative points is about $8 \%$, and about $27 \%$ of points lie in the middle zone between positive and negative. There are many positive points that can be mentioned (65\%), especially those relating to setting vision and goals, assessing needs and resources, defining requirements and technical specifications, defining roles and responsibilities, and managing contracts. Negative points (8\%) concentrate on the time-delay in the project schedule and in the lack of risk analysis. Different alternative scenarios could be prepared to face some obstacles such as when there is a delay by the contractor, when there is a shortage of spaces available to accommodate the new equipment, or when moving to a new building. Finally, there are still some points of incompleteness $(27 \%)$ which lie in the middle zone between positive and negative such as shortages in SWOT Analysis, compatibility of new technology, achievement of milestones and benchmarks, and training and support. Each of the negative points and the points of incompleteness represent deficiencies that must be dealt with before going ahead with the project. This can be achieved through a comprehensive update for the technology plan of the project.

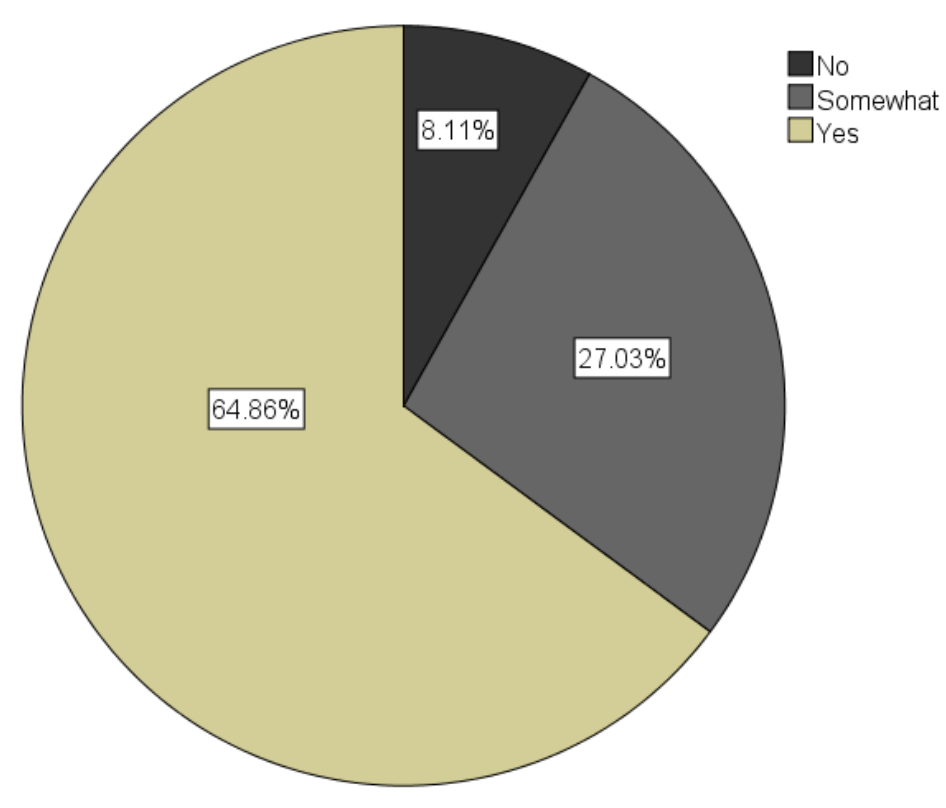

Fig. 1. Evaluation of the eCollege Project of FED in KAU using the ITPEC.

It is worth mentioning that despite the shortcomings the eCollege Project has put FED on the path of development and modernization, has established a culture of challenge for implementing a large technology project, and has raised the technical and managerial skills of many individuals who involved in the implementation processes. Undoubtedly there are useful lessons from this experience and, if learned carefully, FED can take the advantage of them to go forward to future prospects.

\section{Conclusion}

It was clear in this study that a project manager in an academic institution needs simple and effective tools to assist him/her in evaluating the progress of the project starting from its early stages from the implementation phases until the project is completed. So, this 
study introduced an Instructional Technology Project Evaluation Checklist (ITPEC) as an evaluation tool. The checklist was developed and validated through multiple phases. The final version of the checklist includes 48 checkpoints in the form of questions grouped into three groups according to the three phases of the project structure: Planning Phase, Implementation Phase, and Evaluation Phase. Then, ITPEC was used in the evaluation of a case study implementation of an eCollege Project, which was implemented at the Faculty of Environmental Design, King Abdulaziz University in Saudi Arabia. Quantitative analysis of the data derived from the application of ITPEC to the case study showed many positive aspects and also some shortcomings to be addressed in the future. This paves the way for further research on preparation of a new road map for the eCollege also further evaluation for subprojects included in the project in addition to summative assessment when completed.

\section{References}

[1] Modesto, S.T. and Tichapondwa, S.P. (2009) Successful Project Management, Insights from Distance Education Practices, Retrieved August 16, 2014 from:

http://www.col.org/sitecollectiondocuments/successpr ojmgt.pdf

[2] Martz, W. (2010) Validating an evaluation checklist using a mixed method design, Evaluation and Program Planning 33, 215-222.

[3] Ekberg, J. ,Gursky, E.A. and Timpka, T. (2014) Pre-launch evaluation checklist for online healthpromoting communities, Journal of Biomedical Informatics 47, 11-17.

[4] Jaatun, M.G., Rostum, J., Petersen, S. and Ugarelli, R. (2014) Security checklists: a compliance alibi, or a useful tool for water network operators? Procedia Engineering 70, $872-876$.

[5] Hales, B. M. and Pronovost, P. J. (2006). The checklist: A tool for error management and performance improvement. Journal of Critical Care, performance $231-235$.

[6] Keil, M., Li, L., Matthiassen, L. and Zheng, G. (2008). The influence of checklists and roles on software practitioner risk perception and decision- making, Journal of Systems and Software, 81, 908919

[7] Sanders, J. R. (2001). A vision for evaluation. American Journal of Evaluation, 22, 363-366.

[8] Scriven, M. (2007). The logic and methodology of checklists. Retrieved August 17, 2014 from http://www.wmich.edu/evalctr/archive checklists/pap ers/logic\&methodology_dec07.pdf.

[9] Stufflebeam, D. L. (2000) Guidelines for developing evaluation checklists: The checklist development checklist. Retrieved August 17, 2014 from checklist. Retrieved August 17, 2014 from
http://www.wmich.edu/evalctr/archive_checklists/guid elines_cdc.pdf.

[10] Zhao, J., Qi, Z. and De Pablos, P.O. (2014) Enhancing enterprise training performance: Perspectives from knowledge transfer and integration, Computers in Human Behavior 30, 567-573.

[11] Liu, S. (2011) Factors related to pedagogical beliefs of teachers and technology integration, Computers \& Education 56, 1012-1022.

[12] Lareki A., Martinez de Morentin J.I. and Amenabar, N. (2010) Towards an efficient training of university faculty on ICTs, Computers \& Education 54, 491-497.

[13] Wang, T. (2009) Rethinking teaching with information and communication technologies (ICTs) in architectural education, Teaching and Teacher Education 25, 1132-1140.

[14] Horne M. and Hamza N. (2006) Integration of Virtual Reality within the Built Environment Curriculum, ITcon 11/May 2006, pp. 311-324, Retrieved August 15, 2014 from: http://www.itcon.org/data/works/att/2006_23. content. 01137.pdf

[15] Howella S. L., Sabab F., Lindsay N. K. and Williams P. B. (2004) Seven Strategies for Enabling Faculty Success in Distance Education, Internet and Figher Education 7,33-49. Higher Education 7, 33-49.

[16] Garba S. B. (2004) Virtual Reality Implementation in the Architectural Curriculum, 1st ASCAAD International Conference, e-Design in Architecture, KFUPM, Dhahran, Saudi Arabia. 15, 2014 from: pp. 295-307. Retrieved August 15, 2014 from:
http://www.ascaad.org/conference/2004/pdfs/paper18 .$p d f$

[17] Bennett J. and Bennett L. (2003) A review of factors that influence the diffusion of innovation when structuring a faculty training program, Internet and Higher Education, 6, 53-63.

[18] Koszalka T. A. and Grabowski B. L. (2003) Combining Assessment and Research during Development of Large Technology Integration Projects, Evaluation and Program Planning, 26, 203-213. 
[19] Ertmer, P. A. (1999) Addressing First- and SecondOrder Barriers to Change: Strategies for Technology Integration, ETR\&D, 47/4, 47-61.

[19] Rogers, D. L. (2000) A Paradigm Shift: Technology Integration for Higher Education in the New Millennium, Educational Technology Review, Spring/Summer 2000, pp. 19-33.

[20] Marcelino-Sádaba, S., Pérez-Ezcurdia, A., Lazcano, A.M.E. and Villanueva, P. (2014) Project risk management methodology for small firms, International Journal of Project Management 32, 327-340.

[21] Irimia-Diéguez, A.I., Sanchez-Cazorla, A. and Alfalla-Luque, R. (2014) Risk Management in Megaprojects, Procedia - Social and Behavioral Sciences 119, $407-416$

[22] Patanakul, P. (2014) Managing large-scale IS/IT projects in the public sector: Problems and causes leading to poor performance, Journal of High Technology Management Research, 25, 21-35.

[23] Reza Farzin, M., Safari Kahreh, M., Hesan, M., and Khalouei, A. (2014) A survey of Critical Success Factors for Strategic Knowledge Management implementation: applications for Service Sector, Procedia - Social and Behavioral Sciences, 109, 595-599.

[24] Zou, W., Kumaraswamy, M., Chung, J. and Wong, J. (2014) Identifying the critical success factors for relationship management in PPP projects,
International Journal of Project Management, 32, 265-274.

[25] Gu, V.C., Hoffman, J.J., Cao, Q. and Schniederjans, M.J. (2013) The effects of organizational culture and environmental pressures on IT project performance: A moderation perspective,
International Journal of Project Management. (Article in press), pp. 1-12.

[26] Kalkan, A. and Bozkurt, O.C., (2013) The choice and use of strategic planning tools and techniques in Turkish SMEs according to attitudes of executives, Procedia - Social and Behavioral Sciences, 99, 1016 $-1025$.

[27] Lee, S. and Yu, J. (2012) Success model of project management information system in construction, Automation in Construction, 25, 82-93.

[28] Lan, J. (2001) Web-based Instruction for Education Faculty: A Needs Assessment, Journal of Research on Computing in Education, 33/4, International Society for Technology in Education, pp. 385-398. Retrieved $\begin{array}{lccc}\text { August } & 16, & 2014 & \text { from: } \\ \text { http://www.etc.edu.cn/articledigest13/english2.htm }\end{array}$

[29] Schmidt, R., Lyytinen, K., Keil, M. and Cule, P. (2001) Identifying software project risks: An international Delphi study, Journal of Management Information Systems, 17 (4), 5-36.

[30] Maatouk, M. (2006) E-College as an Integrated Institutional Solution for Providing E-Services in the Faculty of Environmental Design- KAU, The 3rd eServices Symposium in the Eastern Province- Future of eServices: the Next Step? Khubar, Saudi Arabia, 26-27 February 2006. 
قائمة تدقيق لإدارة المشاريع التقنية بالمؤسسات الأكاديمية: تجربة كلية تصاميم البيئة بجامعة الملك عبد العزيز بالمملكة العربية السعودية

\section{محمد محمود حسن معتوق}

كلية تصاميم البيئة بجامعة الهلك عبد العزيز - جدة - المملكة العربية السعودية

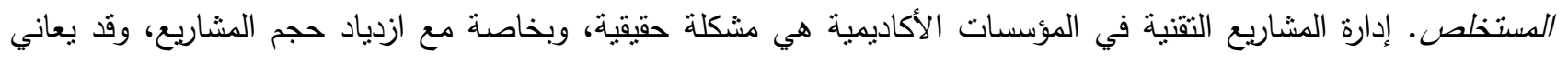

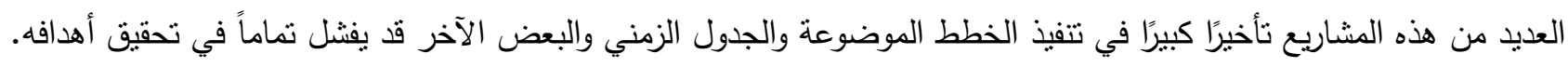

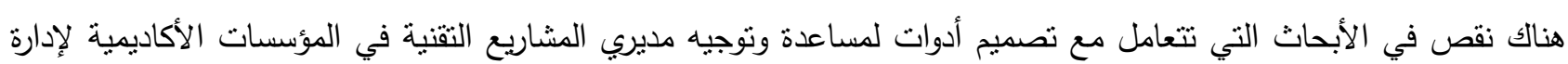

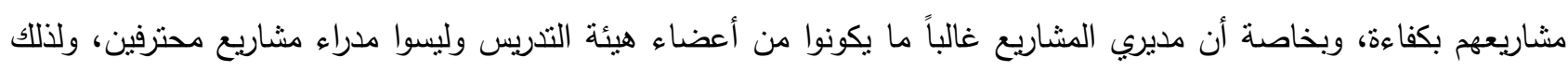

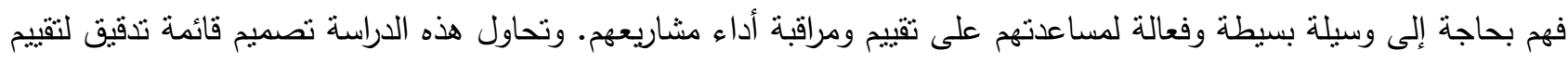

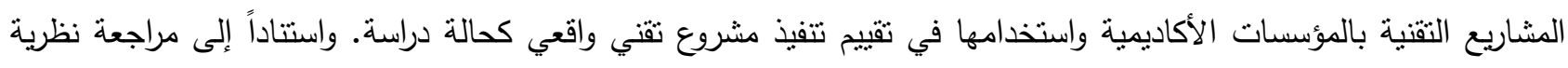

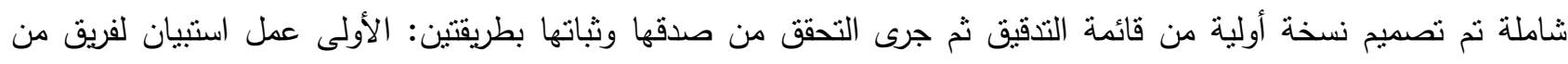

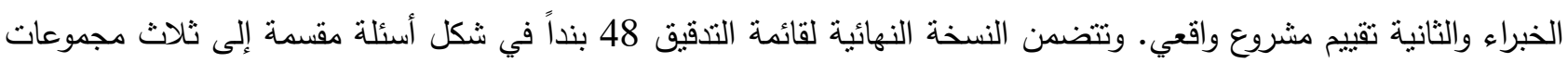

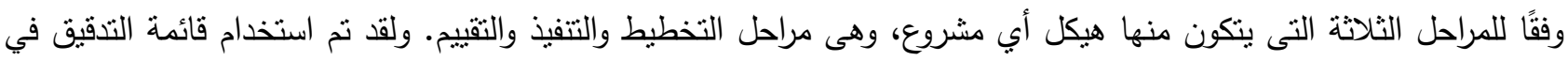

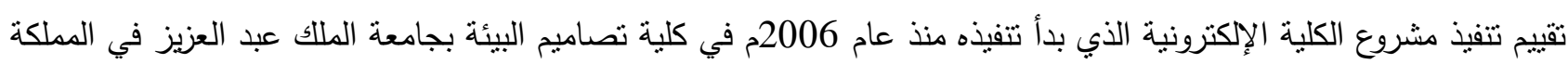
العربية السعودية، ولقد أظهر النحليل الكمي للبيانات المستدة من تثيبيم المشروع العديد من الجوانب الإيجابية، وأيضا بعض العض أوجه القصور التي ينبغي معالجتها في المستقبل. كلمات مفتاحية: إدارة المشاريع، دمج النكولوجيا بالعملية التعليمية، التعليم المعماري. 
